VIII Congresso Brasileiro de Informática na Educação (CBIE 2019)

Anais do XXV Workshop de Informática na Escola (WIE 2019)

\title{
ELIS: Uma ferramenta inclusiva para o ensino de lógica de programação aos surdos
}

\author{
Luciano A. Teran' ${ }^{1}$, Fabiola P. Oliveira ${ }^{2}$, Yomara P. Pires ${ }^{1}$, Rubens A. O. Faro ${ }^{3}$ \\ ${ }^{1}$ Faculdade de Computação (FACOMP) - Universidade Federal do Pará (UFPA) \\ 68746-360 - Castanhal - PA - Brazil \\ ${ }^{2}$ Instituto de Ciências Exatas e Naturais (ICEN) - Universidade Federal do Pará (UFPA) \\ 66075-110 - Belém - PA - Brazil \\ ${ }^{3}$ Faculdade de Pedagogia (FAPED) - Universidade Federal do Pará (UFPA) \\ 68746-360 - Castanhal - PA - Brazil \\ lucteransi@gmail.com, \{fpoliveira, yomara\}@ufpa.br,rubfaro@hotmail.com
}

\begin{abstract}
This paper demonstrates the production and validation of the Teaching Logic for Deaf Inclusion (ELIS) tool. The cited software should stimulate in the teaching-learning process of deaf students who are enrolled in basic education II. In addition, selective collection is used as the main objective for the teaching of programming logic and its sequence of steps. Software development followed the primordial stages of software engineering, such as requirements elicitation, prototyping, coding, and testing. The data collection with users and validation of the tool were carried out in the elementary schools of the municipality of Castanhal, located in the state of Pará and had satisfactory results, since the students were able to carry out the proposed phases.
\end{abstract}

Resumo. Este artigo demonstra a produção e validação da ferramenta Ensinando Lógica para Inclusão de Surdos (ELIS). O software citado deve estimular no processo de ensino-aprendizagem de alunos surdos que se encontram matriculados na educação básica II. Além do mais, utiliza-se a coleta seletiva como o objetivo principal para o ensino da lógica de programação e sua sequência de passos. O desenvolvimento do software seguiu as etapas primordiais da engenharia de software, como a elicitação de requisitos, prototipação, codificação e teste. A coleta de dados com usuários e validação da ferramenta foram realizados nas escolas de ensino fundamental do município de Castanhal, localizado no estado do Pará e tiveram resultados satisfatórios, pois os alunos conseguiram realizar as fases propostas.

\section{Introdução}

$\mathrm{Na}$ sociedade contemporânea, a computação é uma ciência que diariamente proporciona inovação e conhecimento para as pessoas. Quanto mais os seres humanos conhecem as tecnologias digitais da informação e comunicação (TDICs), mas eles estão expostos aos benefícios que a sociedade atual proporciona, como por exemplo o mercado de trabalho. De acordo com [Gresse et al. 2018], pessoas que conhecem os fundamentos da computação fazem parte de um grupo alfabetizado em tecnologia da informação no qual possuem capacidades técnicas para produzir ferramentas que atendam as carências de outros cidadãos. 
VIII Congresso Brasileiro de Informática na Educação (CBIE 2019)

Anais do XXV Workshop de Informática na Escola (WIE 2019)

A educação básica deve possibilitar o desenvolvimento de habilidades nas crianças, visto que elas serão os profissionais do futuro. Dessa forma, as escolas de ensino fundamental devem ensinar matérias obrigatórias e também incluir outras áreas extracurriculares para desenvolver competências pessoais e profissionais nos alunos e, assim, prover uma sociedade melhor que a atual. A educação ambiental (EA) e lógica de programação (LP) são áreas que podem conceber futuras gerações mais conscientes e criativas. Enquanto a EA gera pessoas com raciocínio crítico e menos consumistas dos recursos naturais [Silva et al. 2019], a LP possibilita indivíduos com raciocínios lógicos e capacidades de evoluir as ferramentas computacionais através de novas tecnologias digitais de informação e comunicação (NTDICs). Os computadores podem ser ferramentas interessantes para estimular o aprendizado de alunos, visto que os recursos computacionais estão no dia-a-dia dos estudantes e, neste contexto, devem ser considerados como instrumentos potenciadores e auxiliadores do ensino [Neto et al. 2018].

Todos os alunos independentemente de questões físicas, intelectuais ou sociais precisam estar inclusos em um ensino de qualidade, dentre eles os surdos, que possuem aspectos culturais e linguísticas específicos e precisam ter apoio especializado do professor, intérprete ou ferramentas acessíveis para o ensino inclusivo de um determinado conteúdo. De acordo com a pesquisa do INEP (2019), no Brasil, existem total de 20.893 surdos matriculados em classes regulares do ensino básico, e 6,86\% desses estudantes estão matriculados no estado do Pará. Analisando os dados citados, é possível identificar a enorme parcela de surdos estudantes da educação básica brasileira e paraense. Além do mais, a pesquisa também viabiliza a importância da inclusão dos surdos no processo de aprendizagem da LP, pois eles utilizam a tecnologia, mas talvez não saibam como ela funciona.

Diante deste contexto, o presente trabalho busca incluir sócio-digitalmente o surdo no processo de aprendizado da lógica básica de programação, uma vez que a LP torna-se uma realidade importante no desenvolvimento de competências intelectuais, além do desenvolvimento da criatividade, organização e o trabalho em equipe, tão importantes nos dias atuais.

Este artigo está dividido da seguinte forma. A Sessão 2 apresenta a metodologia utilizada no trabalho, assim como a lista com as etapas de desenvolvimento e validação da ferramenta. A Sessão 3 fica responsável por mostrar as técnicas e tecnologias utilizadas para o desenvolvimento do software. Na Sessão 4 foi demostrado as principais funcionalidades do jogo. Na Sessão 5 apresenta-se os resultados dos testes realizados com os alunos surdos da educação básica. A Sessão 6 finaliza este artigo mostrando a conclusão deste trabalho.

\section{Metodologia do Trabalho}

Este artigo apresenta um trabalho de natureza aplicada, pois desenvolveu-se um software voltado para o ensino da LP e coleta seletiva. Definiu-se o objetivo como descritivo, pois foi necessário estudar a cultura surda, na qual analisou-se os seus hábitos e a língua no qual eles utilizam para se expressar e comunicar, a Linguagem Brasileira de Sinais (LIBRAS). Também, trabalhou-se com abordagem quantitativa, visto que os dados providos pela etapa de testes geraram análises numéricas. Para finalizar, a pesquisa seguiu um procedimento experimental, já que não há relatos, até 
VIII Congresso Brasileiro de Informática na Educação (CBIE 2019)

Anais do XXV Workshop de Informática na Escola (WIE 2019)

então, de softwares que ensinassem lógica de programação juntamente com coleta seletiva aos surdos da educação básica.

O desenvolvimento e avaliação do jogo seguiram as seguintes etapas, no processo de desenvolvimento: levantamento de requisitos; desenvolvimento do modelo relacional, diagramas de atividades e casos de uso; criação de protótipos para validar a aparência e organização do sistema; construção do código-fonte do sistema. No processo de validação e testes: aplicação do questionário inicial para verificar o acesso dos surdos à tecnologia e também o conhecimento prévio em programação e coleta seletiva; interação dos alunos com a ferramenta por meio dos testes. Por fim, com o intuito de verificar a qualidade do jogo e o aprendizado do aluno após contato com a ferramenta desenvolvida, denominada de ELIS, foi realizada a aplicação do questionário final.

Os alunos voluntários que participaram desta pesquisa eram de turmas do $6^{\circ}$ ao $9^{\circ}$ ano, dispostos em 5 escolas de ensino fundamental do município de Castanhal-PA. Por intermédio da Secretaria Municipal de Educação (SEMED) do munícipio, foi possível obter uma relação quantitativa de escolas que possuíam estudantes surdos matriculados nas séries do $5^{\circ}$ ao $9^{\circ}$ ano. Em contato com as escolas municipais, os responsáveis pelos alunos ou os próprios surdos (se maior de idade), indicaram interesse de participar dos testes quando assinaram o Termo de Consentimento e Livre Esclarecimento (TCLE). Dessa forma o software ELIS teve sua validação através do contato direto com o público ao qual se destina.

\section{Construção do software}

\subsection{Elicitação de requisitos}

A elicitação de requisitos é uma etapa, no processo de desenvolvimento de softwares, responsável pelo levantamento de suas funcionalidades, sejam elas funcionais (responsáveis pelo o que o sistema fará) ou não funcionais (restrições técnicas do sistema, como por exemplo segurança e tempo de resposta). Neste trabalho, este levantamento foi realizado através de técnicas de análise comportamental do meio ambiente e dos usuários que farão uso do sistema.

A elicitação de requisitos do projeto deu-se por meio de pesquisa bibliográfica para analisar como é a cultura, qual é a forma de comunicação do surdo e como está atualmente o contexto educacional e de inclusão. Os principais resultados coletados foram que o surdo utiliza atualmente a LIBRAS, como a primeira língua (L1), e a importância do intérprete no processo de inclusão escolar dessas pessoas. Segundo o parágrafo único da lei $\mathrm{n}^{\circ} 10.436$, a LIBRAS é a maneira de: “[...] comunicação e expressão, em que o sistema linguístico de natureza visual-motora, com estrutura gramatical própria, constitui um sistema linguístico de transmissão de ideias [...]" (Brasil 2002). Além disso, de acordo com a lei $\mathrm{n}^{\mathrm{o}} 12.319$, é dever do intérprete "interpretar, em Língua Brasileira de Sinais - Língua Portuguesa, as atividades didáticopedagógicas e culturais desenvolvidas nas instituições de ensino nos níveis fundamental, médio e superior [...]” (Brasil 2010).

\subsection{Estrutura comportamental}

De acordo com Lima (2008), os casos de uso representam “[...] um conjunto de funções que o sistema deve executar para atender aos requisitos do cliente". Portanto, os 
VIII Congresso Brasileiro de Informática na Educação (CBIE 2019)

Anais do XXV Workshop de Informática na Escola (WIE 2019)

diagramas de casos de uso devem demonstrar as funções essenciais do sistema. Neste modelo de diagrama existem os atores, que são os usuários que interagem diretamente com as funções do sistema. A modelagem de casos de uso do jogo é apresentada na Figura 1.

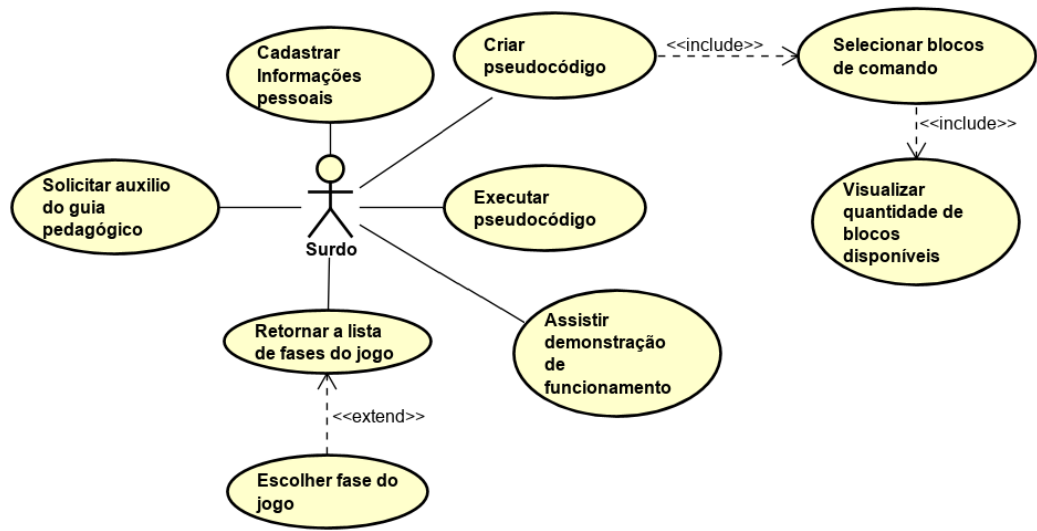

Figura 1. Casos de usos da ELIS

Lima (2008) explica o diagrama de atividades como um recurso que "permite modelar o comportamento do sistema, denotando os caminhos lógicos que um processo pode seguir". No software ELIS, um dos principais diagramas de atividades é a ação de "criar o pseudocódigo" da partida, como mostra a Figura 2. O surdo deve iniciar a fase, montar seu algoritmo (pseudocódigo) e executar o mesmo. Após isso, o compilador do jogo verificará o pseudocódigo elaborado pelo aluno e, se o código for correto, aparecerá um aviso parabenizando-o; senão, avisará que o código montado está errado.

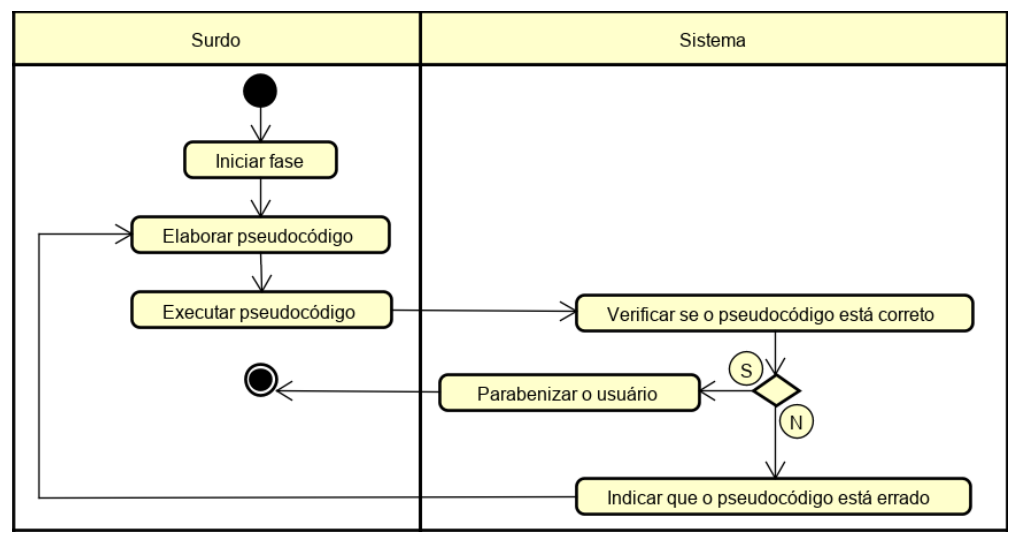

Figura 2. Diagrama de atividades da aplicação

\subsection{Protótipo}

A prototipação é uma técnica utilizada por desenvolvedores para tornar uma ideia abstrata, somente registrada em documentos e diagramas, bem próxima do produto final. Além disso, os protótipos "reduzem as incertezas do projeto, pois são uma forma ágil de abandonar alternativas que não são bem recebidas e, portanto, auxiliam na identificação de uma solução final mais assertiva" (Vianna et al. 2012).

Existem diversas formas para representar um protótipo, dentre elas as possíveis telas do jogo feitas à mão ou em softwares de edição de imagem. Durante a construção deste jogo, aplicou-se os níveis de fidelidade de prototipação baixo e médio para estabelecer aspectos visual e conceituais. A tabela abaixo exemplifica melhor estes níveis. 
VIII Congresso Brasileiro de Informática na Educação (CBIE 2019)

Anais do XXV Workshop de Informática na Escola (WIE 2019)

Tabela 1. Níveis de fidelidade para prototipação (Vianna et al. 2012)

\begin{tabular}{|c|l|l|}
\hline Fidelidade & \multicolumn{1}{|c|}{ Descrição } & \multicolumn{1}{|c|}{ Exemplo } \\
\hline Baixa & $\begin{array}{l}\text { Representação simples. Apresenta-se um } \\
\text { objeto para realizar uma analogia da ideia. }\end{array}$ & $\begin{array}{l}\text { Técnica de wireframe feito à mão; } \\
\text { storyboard. }\end{array}$ \\
\hline Média & $\begin{array}{l}\text { Procura-se representar aspectos para } \\
\text { validadar a ideia. }\end{array}$ & $\begin{array}{l}\text { mock-up, layout básico feitos por um } \\
\text { software de edição de imagem. }\end{array}$ \\
\hline Alta & $\begin{array}{l}\text { Tenta-se produzir um objeto mais } \\
\text { próximo do resultado final do software. }\end{array}$ & $\begin{array}{l}\text { mock-up com algumas funcionalidades } \\
\text { do software final. }\end{array}$ \\
\hline
\end{tabular}

A Figura 3 é um exemplo da primeira etapa de prototipação do jogo. O desenho feito com caneta e papel, cujo a característica de fidelidade é baixa, definiu a disposição e funções dos elementos de telas necessários para o funcionamento do software ELIS.

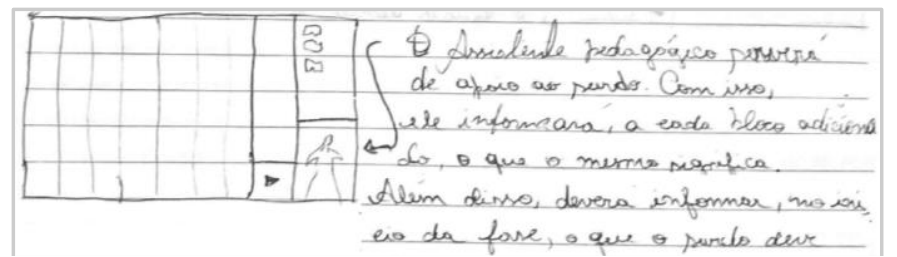

Figura 3. Protótipo da tela de fase do software ELIS feito à mão

Após a construção do protótipo de baixa fidelidade, foi iniciado o de nível médio, onde criou-se 4 telas essenciais para validar a concepção do software e sua aparência. A Figura 4 demonstra um exemplo da tela inicial, validado pela etapa de protótipo com grau de fidelidade média.

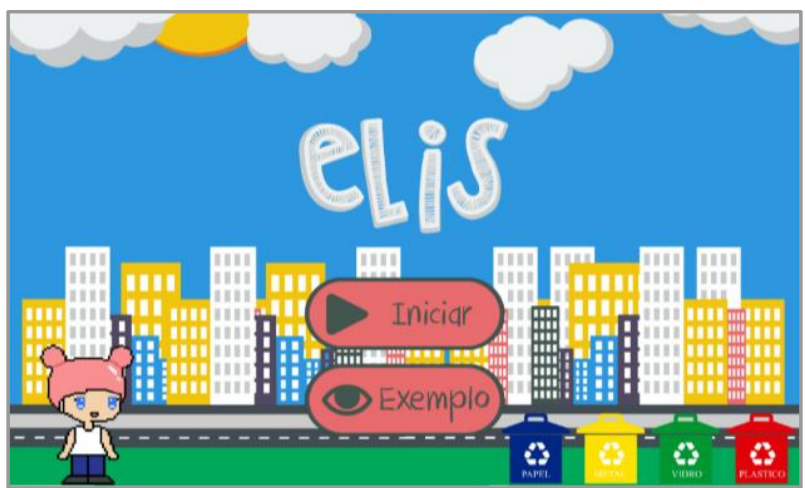

Figura 4. Mocku-up da tela inicial

\subsection{Ferramentas para codificação}

O Construct 2 é uma ferramenta que produz jogos e animações em 2D por meio da linguagem de marcação HTML5 [Sierra 2019]. Ele é considerado uma excelente ferramenta para o ensino de programação, visto que os jogos e animações são produzidos facilmente por meio de blocos de comandos. Nele é possível escolher diferentes tipos de plataformas, validando um requisito não funcional do sistema que solicitava o desenvolvimento do jogo para diferentes navegadores de Internet. Outro motivo que privilegiou a escolha dessa game engine para o projeto é seu suporte a requisições a webservices, via AJAX. Neste contexto, foi possível deixar o jogo mais dinâmico, armazenando o tempo e quantidade de tentativas das fases em um servidor de banco de dados (SBD).

A linguagem de programação escolhida para produzir o webservice foi o PHP, dado que ele é uma linguagem de programação orientada para o desenvolvimento de aplicações web [PHP 2019]. Com o seu suporte ao PDO (PHP data objects), foi 
VIII Congresso Brasileiro de Informática na Educação (CBIE 2019)

Anais do XXV Workshop de Informática na Escola (WIE 2019)

possível efetuar a comunicação do webservice com o banco de dados (BD). Finalizando, utilizou-se o sistema gerenciador de banco de dados (SGBD) MySQL para manipular os dados do software ELIS. O BD criado possui apenas as tabelas jogador e fase para armazenar o nickname (apelido), série, tentativas e tempo médio por fases, podendo assim ser realizada uma avaliação futura de desempenho dos usuários.

\section{O software ELIS}

O software ELIS é uma ferramenta computacional que busca ensinar LP para os surdos de forma inclusiva, porquanto em nenhum momento tem como objetivo o ensino de uma linguagem de programação fixa (como por exemplo o PHP, C\# e Java), mas sim o pensamento para resolução de problemas através do raciocínio lógico, visando a aprendizagem por meio da experimentação e estímulo tecnológico.

O jogo possui uma personagem batizada pela mesma sigla do jogo, a Elis. De modo geral, ela é o meio visual com o qual os usuários devem interagir, sendo a personagem o ponto central de contato entre os blocos selecionados e a execução dos comandos definidos previamente. Os blocos são as ações que farão efeitos diferenciados no cenário do jogo e nas diferentes fases, alguns exemplos são andar, pegar e despejar. Entretanto, também existem os parâmetros dos blocos, que servem para indicar a direção na qual a Elis deve se mover e o material (papel, plástico, metal e vidro) que ela deve despejar.

Utilizou-se a coleta seletiva como contexto da programação, com o intuito que os alunos raciocinassem e colocassem em prática uma série de passos (andar, pegar, despejar) com um propósito comum: a destinação correta dos resíduos sólidos recicláveis. $\mathrm{O}$ artigo $3^{\circ}$ da lei 12.305, que institui a Política Nacional de Resíduos Sólidos (PNRS), “[...] a coleta seletiva é a coleta de resíduos sólidos previamente segregados conforme sua constituição ou composição" (Brasil 2010). Analisando a referida citação, o papel, plástico, vidro e metal possuem características de composições diferenciadas e, deste modo, devem ser despejados em repositórios (lixeiras) diferentes.

Após definido a coleta seletiva como aspecto principal para estimular o raciocínio lógico, foram desenvolvidos 6 níveis, ou fases, a serem realizadas pelos surdos. Na Tabela 2 é explicado o objetivo de cada nível.

Tabela 2. Descrição das dificuldades do jogo

\begin{tabular}{|c|l|}
\hline Nível & \multicolumn{1}{|c|}{ Objetivo } \\
\hline $\mathbf{1}$ & A personagem Elis deve andar, pegar o resíduo de papel e despejá-lo na lixeira azul \\
\hline $\mathbf{2}$ & A personagem Elis deve andar, pegar o resíduo de plástico e despejá-lo na lixeira vermelha \\
\hline $\mathbf{3}$ & A personagem Elis deve andar, pegar o resíduo de vidro e despejá-lo na lixeira verde \\
\hline $\mathbf{4}$ & A personagem Elis deve andar, pegar o resíduo de metal e despejá-lo na lixeira amarela \\
\hline $\mathbf{5}$ & $\begin{array}{l}\text { A personagem Elis deve andar, pegar os materiais de vidro e metal e despejá-los nas lixeiras } \\
\text { corretas }\end{array}$ \\
\hline $\mathbf{6}$ & $\begin{array}{l}\text { A personagem Elis deve andar, pegar todos os quatro materiais e despejá-los nas lixeiras } \\
\text { corretas }\end{array}$ \\
\hline
\end{tabular}

A Figura 5 mostra a tela onde são realizadas as 6 partidas do jogo. A cada fase, o surdo tem um aprendizado diferente sobre separação de materiais recicláveis e programação. Como explicado na Tabela 2, as 4 primeiras fases ensinam em qual container deve ser despejado o resíduo de papel, plástico, vidro ou metal. Ademais, as 
VIII Congresso Brasileiro de Informática na Educação (CBIE 2019)

Anais do XXV Workshop de Informática na Escola (WIE 2019)

duas últimas partidas ensinam a estrutura de comparação da programação, pois os alunos devem despejar dois ou quatro materiais distintos em suas respectivas lixeiras.

Ao lado direito da tela da fase 1 do jogo (Figura 5) vê-se a intérprete indicando, em LIBRAS, o que deve ser feito na partida. A intérprete e o professor coordenador do Grupo de Estudos e Pesquisa em Língua de Sinais e Educação de Surdos (GEPLISES), da Universidade Federal do Pará (UFPA), ajudaram de forma voluntária a organizar os sinais que o sistema deve ter. No total, foram 52 sinais mapeados, gravados e armazenados no jogo, os quais foram cedidos através de termo de uso de imagem.

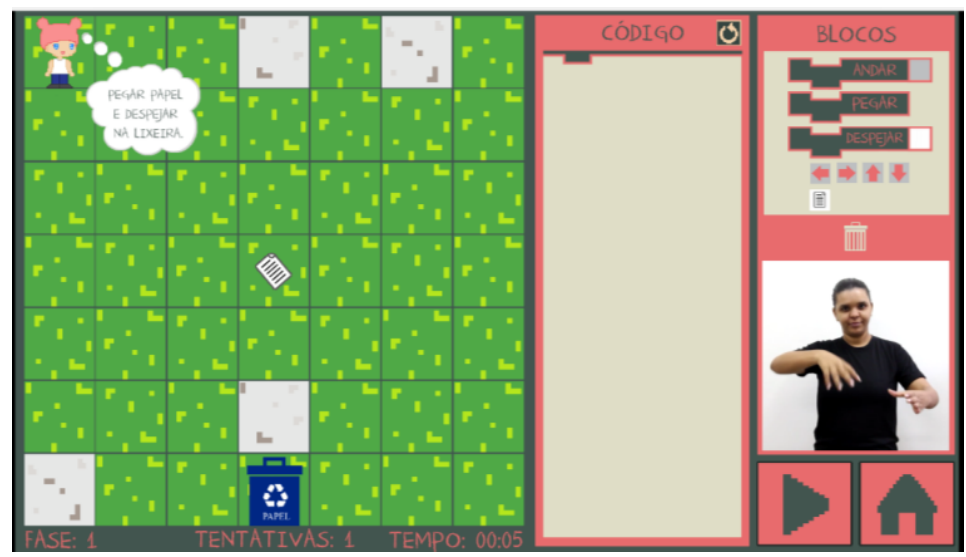

Figura 5. Tela da fase 1 do jogo

\section{Resultados}

A etapa de avaliação da ferramenta dividiu-se em três categorias de resultados: avaliação por meio de um questionário pré-projeto de cunho socioeconômico, inferência de dados armazenados no BD durante a utilização do jogo e análise das informações do questionário pós-projeto para avaliar a qualidade do jogo e a aprendizagem do aluno. Durante o período de 21 a 29 de junho de 2019, participaram deste projeto 10 alunos de $6^{\circ}$ ao $9^{\circ}$ ano. Os questionários respondidos pelos alunos tinham perguntas de múltipla escolha ou única escolha com ou sem escala Likert, representado por expressões faciais da personagem Elis.

\subsection{Questionário pré-projeto}

A primeira categoria de resultados, dados socioeconômicos, apontou que $70 \%$ dos alunos eram do sexo masculino e que $30 \%$ do sexo feminino. E também, $70 \%$ dos surdos tinham 17 anos ou mais, 20\% tinham entre 13 a 14 anos e $10 \%$ estavam com 15 ou 16 anos. Outrossim, 50\% encontravam-se nas turmas do $8^{\circ}$ ano, $30 \%$ estavam no $9^{\circ}$ ano e $10 \%$ entre $6^{\circ}$ ou $7^{\circ}$ ano. Esses dados demonstram a veracidade das palavras de [Lacerda, 2006], no qual indica que os surdos sofrem defasagem escolar e cognitiva pelo fato de terem que aprender a língua de sinais para depois aprenderem o português.

Na pergunta de múltipla escolha, $80 \%$ dos surdos indicaram que possuem um Smartphone, 60\% indicaram que possuem smartTV, $40 \%$ possuem computador e $10 \%$ não possuem nenhum dos equipamentos citados. Sobre a utilização de eletrônicos para estudar ou jogar em casa, $50 \%$ dos alunos disseram que utilizam bastante, $40 \%$ utilizam e $10 \%$ utilizam razoavelmente os dispositivos. Sobre o tempo de uso por dia, $40 \%$ disseram usar 8 horas ou mais, 20\% entre 4 a 8 horas, $20 \%$ entre 2 a 4 horas e $20 \%$ utilizam cerca 2 horas ou menos horas. Quando questionados sobre o interesse em 
VIII Congresso Brasileiro de Informática na Educação (CBIE 2019)

Anais do XXV Workshop de Informática na Escola (WIE 2019)

serviços tecnológicos (jogos e softwares), $90 \%$ relatou possuir muito interesse e $10 \%$ demostrou um certo nível de interesse. De acordo com a pergunta sobre os níveis de dificuldades para se adaptar a novos aplicativos ou jogos, $70 \%$ indicaram que não possuem nenhuma dificuldade, $10 \%$ possuem dificuldades razoáveis e $20 \%$ possuem muita dificuldade.

Os alunos indicaram que não sabiam o que era a lógica de programação e nunca participaram de cursos, oficinas ou palestras que ensinasse o mesmo. Também foi perguntado se eles conheciam alguma ferramenta que ensinasse lógica de programação, $90 \%$ disse que não conheciam nenhuma e apenas $10 \%$ indicaram que conheciam a placa microcontroladora programável, de hadware e software, chamada Arduíno (2019).

Para finalizar, perguntou-se sobre a coleta seletiva. As respostas foram que $40 \%$ conheciam razoavelmente, $20 \%$ não conheciam nem um pouco do que o assunto se tratava, $20 \%$ não conheciam, $10 \%$ conheciam e outros $10 \%$ conheciam bastante. Sobre a destinação correta dos materiais (papel, plástico, vidro e metal), $80 \%$ dos surdos indicaram que não sabiam qual era a lixeira correta para os materiais recicláveis e $20 \%$ saberiam onde descartar corretamente os materiais.

\subsection{Inferências automatizadas de utilização}

A segunda categoria de resultados se deu através das tentativas e tempo para realizar as partidas do jogo. Antes de usar a ferramenta, foi explicado ao surdo, de forma geral, o que era a coleta seletiva e a lógica de programação. Em seguida, foi apresentado um vídeo exemplificando as partidas, para que eles aprendessem o que deveriam fazer ao iniciar o jogo. Após todas as etapas citadas, o surdo ficou à vontade para utilizar a ferramenta sendo informado que poderiam sanar dúvidas caso assim tivessem. Como resultado geral, $100 \%$ dos participantes conseguiram concluir todas as 6 fases propostas pelo jogo.

Os surdos tiveram mais dificuldades na primeira e quinta fase, visto que as tentativas máximas se encontram nessas partidas (Tabela 3). Isso se deve pelo fato de que a primeira fase é um processo de adaptação do aluno, no qual ele aprenderá o significado dos blocos de comandos e como utilizá-los para montar seu pseudocódigo. Ademais, o motivo pelo qual o $5^{\circ}$ nível teve a média mais alta de tentativas foi pelo fato de nesta ter um aumento da quantidade de lixeiras e materiais para o descarte. As maiores médias de tempo para conclusão das fases ficaram entre os níveis 5 e 6 , com os respectivos tempos de 00:05:44 e 00:06:36.

Tabela 3. Resultados gerais de tentativas e tempos

\begin{tabular}{|c|c|c|c|c|c|c|}
\hline \multirow{2}{*}{ Nível } & \multicolumn{3}{|c|}{ Tentativas } & \multicolumn{3}{c|}{ Tempo } \\
\cline { 2 - 7 } & Mínima & Média & Máxima & Mínima & Média & Máxima \\
\hline 1 & 1 & 1 & 4 & $00: 01: 20$ & $00: 04: 27$ & $00: 08: 59$ \\
\hline 2 & 1 & 1 & 3 & $00: 02: 11$ & $00: 04: 36$ & $00: 07: 53$ \\
\hline 3 & 1 & 1 & 3 & $00: 02: 44$ & $00: 04: 56$ & $00: 07: 30$ \\
\hline 4 & 1 & 1 & 3 & $00: 02: 40$ & $00: 04: 32$ & $00: 08: 20$ \\
\hline 5 & 1 & 1 & 5 & $00: 02: 40$ & $00: 05: 44$ & $00: 12: 31$ \\
\hline 6 & 1 & 1 & 2 & $00: 01: 49$ & $00: 06: 36$ & $00: 13: 48$ \\
\hline
\end{tabular}


VIII Congresso Brasileiro de Informática na Educação (CBIE 2019)

Anais do XXV Workshop de Informática na Escola (WIE 2019)

\subsection{Questionário pós-projeto}

A última categoria de resultados deu-se por meio do questionário pós-projeto. Ele buscava avaliar a usabilidade do software, o aprendizado de lógica de programação e coleta seletiva, providos após sua utilização.

Tratando da facilidade em utilizar a ferramenta, 20\% indicaram que tiveram muita dificuldade, 30\% dos voluntários tiveram dificuldades razoáveis, 10\% acharam que tiveram facilidade e a maior porcentagem, $40 \%$, indicaram facilidade abundante. A surpresa é que o melhor resultado, $40 \%$, foi exatamente a mesmo número de surdos que tem o computador em casa. Ademais, sobre o divertimento do jogo, $10 \%$ dos surdos não acharam nem um pouco divertido, $10 \%$ acharam divertido e $80 \%$ achou muito divertido. $\mathrm{E}$, ao mesmo momento que consideraram o jogo muito divertido, também relataram ser muito desafiador $(70 \%), 10 \%$ acharam desafiador, $10 \%$ indicaram que se sentiram razoavelmente desafiados e, por último, $10 \%$ não se sentiram desafiados.

O maior número dos voluntários $(80 \%)$ relatou que a intérprete e os balões de avisos são muito importantes, $10 \%$ afirmaram que é importante e os outros $10 \%$ indicaram que não tem nenhuma relevância. Ainda, 50\% dos alunos indicaram o jogo como totalmente funcional, $10 \%$ encontraram pouquíssimos bugs e é funcional, $30 \%$ que encontraram defeitos e acham a ferramenta razoavelmente funcional e apenas $10 \%$ indicaram que o jogo tem muitos defeitos e isso pode impedi-los de utilizar corretamente o software.

Os conceitos de lógica de programação ensinados pelo jogo também foram bem avaliados pelos alunos, no qual 70\% informou que entendeu bastante sobre lógica de programação a qual é uma sequência de etapas com um propósito, outrossim, esse fato é validado pelo banco de dados, visto que todos os surdos conseguiram completar as partidas do software, independentemente do tempo ou quantidade de tentativas, $10 \%$ disseram que entenderam, $10 \%$ entenderam razoavelmente e $10 \%$ não entenderam a lógica de programação. Entretanto, 70\% dos entrevistados disseram que conseguem, após a utilização da ferramenta, colocar o raciocínio de programação em prática e outros $30 \%$ afirmaram ainda ter dúvidas, mas acham que conseguem colocar em prática em outros contextos.

Sobre a coleta seletiva, $70 \%$ dos surdos indicaram que aprenderam fortemente a separar os materiais recicláveis, $10 \%$ disseram que aprenderam razoavelmente, mas ainda tem dúvidas, e $20 \%$ afirmaram que ainda não aprenderam a separar e despejar os resíduos sólidos de papel, plástico, vidro e metal corretamente. Também, $60 \%$ dos alunos tem muito interesse, $20 \%$ tem interesse e $20 \%$ não tem interesse de colocar em prática a coleta seletiva em seu cotidiano. Estes dois questionamentos buscavam avaliar se os participantes se tornaram mais conscientes sobre a separação de materiais recicláveis e os benefícios que ela traz para o meio ambiente e consequentemente a sociedade.

\section{Conclusão}

Este trabalho apresentou o desenvolvimento de um jogo com o objetivo de ensinar a lógica de programação e separação de materiais recicláveis aos surdos que se encontram matriculados na educação fundamental II.

Por outro lado, ajudou a formulação do pensamento computacional através da resolução de problemas por meio de algoritmos e, no ponto de vista da sustentabilidade, 
VIII Congresso Brasileiro de Informática na Educação (CBIE 2019)

Anais do XXV Workshop de Informática na Escola (WIE 2019)

a ferramenta procurou sensibilizar sobre a coleta seletiva e sua importância para gerar futuros cidadãos conscientes com o meio ambiente.

Os resultados obtidos com o software ELIS foram bem proveitosos, pois muitos alunos não conheciam os conceitos abordados pelo jogo, mesmo assim conseguiram concluir as fases com poucas tentativas e, após a utilização, também pretendem colocar em prática tanto a lógica de programação $(70 \%$ dos participantes) quanto a coleta seletiva ( $60 \%$ dos participantes), validando desta forma o objetivo deste trabalho que se propôs em apresentar um jogo adaptado para alunos surdos da rede de ensino pública, agregando elementos da lógica de programação e educação ambiental.

Para finalizar, é importante evidenciar que este trabalho também serve como elo comum entre discentes surdos e ouvintes. Dado que, o ouvinte aprende sinais em LIBRAS dos materiais recicláveis e também de outros contextos (andar, pegar, código, cadastro, iniciar, fase, exemplo, etc). E, para o surdo, ele compreende as palavras escritas na Língua Portuguesa que até então não conhecia.

\section{Referencias}

Arduíno. (2019). About Us.

Brasil, República Federativa (2002). Lei No 10.436: Lei de LIBRAS.

Brasil, República Federativa (2010). Lei No 12.305: Institui a Política Nacional de Resíduos Sólidos.

Brasil, República Federativa (2010). Lei No 12.319: Regulamenta a profissão de Tradutor e Intérprete da LIBRAS.

Wangenheim, C. G. et al. (2014). Ensino de Computação com SCRATCH no Ensino Fundamental - Um Estudo de Caso. Revista Brasileira de Informática na Educação.

Instituto Nacional de Estudos e Pesquisas Educacionais Anísio Teixeira (INEP). (2019). Sinopse Estatística da Educação Básica 2018.

Lima, A. S. (2008). UML 2.0 - do Requisito à Solução. Editora Érica.

Neto, M., Santos, C. A. M. Dos, Souza, E. E. De e Fonseca, M. G. (2018). Robótica educacional uma ferramenta para ensino de lógica de programação no ensino fundamental. Anais do XXIV Workshop de Informática na Escola (WIE 2018).

PHP. (2019). O que é o PHP?.

Sierra. (2019). Construct2.

Silva, K. P. M. et al. (2019). Educação Ambiental e sustentabilidade: uma preocupação necessária e contínua na escola. Revista Brasileira de Educação Ambiental.

Vianna, M. et al. (2012). Design Thinking: inovação em negócios. MJV Press. 